\section{THE RELATION OF ACIDOSIS TO THE CARBON DIOXIDE OF THE BLOOD IN DIABETIC COMA.}

By A. P. BEDDARD, M.A., M.D. Cantab., F.R.C.P. Lond, ASSISTANT PHYSICIAN, GUY'S HOSPITAL; PHYSICIAN, WEST LONDON HOSPITAL;

M. S. PEMBREY, M.A., M.D. OxoN.,

teETURER IN PHYSTOLOGY AT GUY's hOSPITAL; AND

E. I. SPRIGGS, M.D. LoND., F.R.C.P. Lond, SENIOR ASSISTANT PHYSICIAN, ST. GEORGE'S HOSPITAL; PHYSICIAN, VICTORIA HOSPITAL FOR CHILDREN, CHELSEA.

Dr. Pavy, in his lectures on the Pathology and Treatment of Diabetes Mellitus, criticised at some length, and adversely, the conclusions we had drawn from our observations on diabetic coma. He has brought forward no new facts and does not deny the accuracy of our observations, but disagrees with the view to which a consideration of the experiments made by ourselves and other workers has led us. The facts that are not in dispute may be briefly summarised as follows. Directly coma sets in the patient shows a wellmarked hyperpnœa. The "alkalinity" of the blood-that is, its power of combining with acids - is reduced, and the quantity of carbon dioxide in the patient's blood is materially diminished. If sufficient alkali such as sodium bicarbonate is given by the mouth or is injected into a vein the "alkalinity" of the blood and its carbon-dioxide content are increased, and the symptoms of coma may disappear, at least temporarily. When coma is imminent the patient's appetite becomes extremely poor, and during coma the metabolism of the body, as judged by the output of dextrose, nitrogen, and carbon dioxide, is greatly decreased.

The interpretation of these fundamental facts on which Dr. Pavy insists is that which has been given by the majority of observers ever since the classical experiments of Walter on the poisoning of animals by acids. According to this view, the prolonged acidosis of diabetes reduces the amount of base which is available in the blood and tissue fluids for combination with carbon dioxide; the blood therefore contains less carbon dioxide, and being unable to transport as much as should be removed from the tissues carbon dioxide begins to accumulate in them. In the case of the respiratory centre carbon dioxide is its normal stimulus, and, therefore, the centre is, at first, stimulated to greater activity. The accumulation, however, of carbon dioxide leads to a cessation of its production; and, as Dr. Pavy says, "death takes place when the non-removal bas attained a sufficient height to reduce the occurrence of activity to a point which is no longer consistent with the continuance of life."

It is possible to draw from this view certain deductions which can be tested experimentally.

In the first place, so long as the body is alive it will continue to produce carbon dioxide. Whenever the blood is unable to remove it as fast as it is produced, carbon dioxide must accumulate in the tissues, and if it accumulates then its tension in the tissues must be raised; both of these deductions are apparently admitted by Dr. Pavy. Unfortunately, there is no method of estimating directly the carbon dioxide tension in the tissues; but it is generally assumed that the tension of carbon dioxide in the renal cells would not be raised without that in the urine being correspondingly increased. We have shown that the tension of carbon dioxide in the urine in diabetic coma is not raised.

In the second place, if the "alkalinity" of the blood begins to fall, and if carbon dioxide begins to accumulate at an increased tension in the tissues, the blood in the capillaries must be exposed to an increased tension of carbon dioxide. And although the reduced "alkalinity" of the blood might prevent its taking up a normal quantity of carbon dioxide, nevertheless such gas as the blood did take up would be under an increased tension. The tension of the carbon dioxide in the blood can be either estimated directly or deduced from an analysis of the alveolar air. By the former method we have found that it is at any rate not increased, and by the latter that it is, as a matter of fact, diminished even to a fifth of its normal value, and that this decrease is greatest during coma, but is obvious for days both before and after the coma.
In the third place, Dr. Pary points out that if an alkali is injected into the blood the symptoms of coma cease temporarily; and this he explains by saying that the alkali has increased the power of the blood to combine with carbon dioxide. If this explanation of the good effect of alkali were true, then, since the blood in the capillaries would be exposed to carbon dioxide in quantities greater than it is capable of taking up, and at a tension above the normal, the venous blood, in addition to containing carbon dioxide at a tension above the normal, should be saturated with carbon dioxide for that abnormal tension. We have shown by direct experiment not only that the tension is not raised but that the blood is not saturated even for a tension of carbon dioxide below the normal. Further, if the arm of a patient is bandaged for a sufficiently long time-such, for instance, as two minutes-before the blood is drawn, the carbon-dioxide content of the blood can be raised even up to the normal. In fact, the blood in coma and the precomatose state can combine with very much more carbon dioxide than it actually contains, as will be seen by reference to our determinations.

These observations render untenable the view which is still advocated by Dr. Pavy, and which we ourselves held until we began to work at the subject. This view is based upon the assumption that the decrease of carbon dioxide in the blood is primarily due to the inability of the blood to combine with more carbon dioxide than it is found to contain. This we have shown to be untrue. Some other explanation of the fundamental facts of diabetic coma is necessary, and this we have already attempted to give.

Blood is both alkaline and acid in the sense that it can combine with acids and alkalies. Physico-chemical investigations upon the relative concentrations of acid and basic ions in blood show that in health its reaction is always roughly neutral, approaching that of distilled water. Strictly speaking, the reaction of blood is alkaline to such a slight degree that it may be referred to as being neutral. The reaction of lymph, tissue-fluids, and protoplasm is presumed to be the same as that of the blood. It is probable that the slightest disturbance of this chemical neutrality affects the metabolic activity of protoplasm, and that but a very little upset of the neutrality tuwards the acid side is incompatible with life. During metabolism carbon dioxide and other acids are continuously produced. In the case of distilled water, the least addition of carbon dioxide or other acid destroys its neutral reaction, but in the case of blood and protoplasm, owing to their carbonates, phosphates, and proteins, considerable quantities of carbon dioxide and other weak acids can be added without altering their reaction and destroying their neutrality. This power of the blood and protoplasm to combine with acids without change of chemical reaction has been called by B. Moore "reactivity" to acids.

During the prolonged and severe acidosis of diabetes the bases become combined with abnormal acids, and are no longer available to combine with the normal acid products of metabolism ; hence the range of " reactivity" to acids of the blood and protoplasm is diminished. On this account during severe acidosis the neutrality of the body would be imperilled by relatively smaller doses of its own metabolic products. The cells would be less capable of withstanding the acid properties of their metabolites and would become more sensitive to the physiological action of all acid substances. In the terminal stages of acidosis the quantity and tension of carbon dioxide in the blood are progressively reduced, not, as we have shown, because the blood cannot take up more carbon dioxide than it is found to contain, but because the rising concentration of acid ions in the blood and protoplasm progressively affects the activities of cells. It has been shown by many observers that the quantity of carbon dioxide in blood under comparable conditions of experiment runs parallel with and may be taken practically as a measure of the power of the blood to neutralise acids. As the power of neutralising acid substances manufactured during metabolism progressively falls tissue activity correspondingly decreases, and less carbon dioxide and other acid substances are produced. Also, the respiratory centre is stimulated to greater activity and the hyperpnoa pumps carbon dioxide out of the blood. We have shown that the diminution of carbon dioxide in the blood is present for days before coma begins and lasts for days after coma has passed off. During coma this change is associated with a great increase of the total pulmonary ventilation and a great fall of the carbon dioxide in the 
alveolar air. We have suggested that the extreme diminution of the carbon dioxide in the blood in coma is in part due to the rapid removal of carbon dioxide by the hyperpnoa, an explanation which Dr. Pavy accepts. Before coma begins and after it has passed off there is still present a marked fall of carbon dioxide in the blood and alveolar air, but it is less in degree than in coma. Further, it may be present when the total pulmonary ventilation is low and cannot therefore be due to an ex. cessive pumping of carbon dioxide out of the body. When such a patient is made to hold his breath, he is not able to stop breathing sufficiently long to raise the percentage of carbon dioxide in his alveolar air to the normal-that is, his respiratory centre owing to the acidosis reacts more readily to carbon dioxide. If he is given oxygen to breathe containing a percentage of carbon dioxide $2 \cdot 5$ per cent. greater than that in his alveolar air, he absorbs the carbon dioxide from the mixture into his blood. We conclude, therefore, that the low percentage of carbon dioxide in the patient's blood and alveolar air is due not to his blood being unable to take up more than it was found to contain, but to a diminished production of carbon dioxide by his tissues and to an increased sensitiveness of his respiratory centre to carbon dioxide.

We have, therefore, shown that in the precomatose and comatose states of diabetes the blood can take up more carbon dioxide than it contains and that there is not an accumulation of carbon dioxide in the tissues. Failing any other explanation, we conclude that the diminution of carbon dioxide in the blood is caused by a decreased production and by the hyperpnoea when present, and that both are alike caused by the acidosis. It is necessary to explain the onset of the hyperpnoa. Haldane and Priestley and others have shown that in health carbon dioxide is the chief stimulus to the respiratory centre. In diabetic coma, hyperpnca begins and continues although the quantity and tension of carbon dioxide in the blood are low and there is no accumulation of carbon dioxide in the tissues. At first sight it is not obviuus how in this case carbon dioxide could be an effective stimulus to the centre. If carbon dioxide could affect the centre only in virtue of a specific chemical action it could not be the stimulus in coma. We have shown that in diabetic coma the respiratory centre is not stimulated to greater activity, as it is in health, by a slight increase of carbon dioxide in the blood. A patient in coma was given air to breathe containing $2 \cdot 6$ per cent. more carbon dioxide than was in his alveolar air and the hyperpnoea was not increased. 'The same patient, three days' later, when he was conscious and his hyperpncea had disappeared, was again given air to breathe containing $2 \cdot 6$ per cent. more carbon dioxide than was in his alveolar air, and his hyperpncea returned at once. Carbon dioxide is also an acid substance, and although it may be the principal, it is by no means the only, acid substance produced even in normal metabolism, much less in severe diabetes. We therefore put forward the view that the effective stimulus to the respiratory centre in coma was the increasing concentration of unneutralised acid substances. Our view was expressed in these sentences: "It is suggested that the following process is taking place in the nerve cells of the medulla. 'The decreased 'reactivity' of the protoplasm of the cells due to the prolonged acidosis renders their reaction more easily disturbed by, and therefore makes them more sensitive to, the stimulating influence of any acid body, including carbon dioxide and other acids produced during metabolism." When criticising this view Dr. Pavy quotes against us the work of Haldane and Priestley, which indicates that in health the activity of the respiratory centre varies directly with the tension of carbon dioxide in the blood. Dr. Pavy therefore calls our explanation of the hyperpnoea in diabetic coma "vague, unsubstantiated, and extraneous." When Dr. Pavy wrote this criticism he was apparently unaware that Haldane, like other observers, had already maintained that carbon dioxide is not the only substance which stimulates the respiratory centre, and that in order to explain the regulation of respiration it is necessary to believe that even in health acid bodies other than carbon dioxide do stimulate the centre. This view was put forward originally by Pflüger, Geppert, and Zuntz, and has been amply confirmed by the recent work of Haldane, Pembrey, and others. In fact, our view of the cause of the hyperpnoea in coma is in strict accord with what is known of the regulation of respiration in health, and with the changes which take place in the body in severe diabetes. Similar changes will be taking place in all the other cells of the body, and we imagine that as the acidosis increases the metabolic activity of the tissues is thereby slowly and progressively diminished until consciousness, and finally life, is no longer possible.

Dr. Pavy in his lectures reaches several conclusions in regard to diabetes in general from which we strongly dissent. But we defer a consideration of the subject until the publica. tion of our observations on diabetic patients, when we propose to raise the points in question.

References.-Beddard and Pembrey : Brit, Med. Jour., vol. ii, 1908 p. 580. Beddard, Pembrey, and Spriggs: THE LANCET, May 16th, 1903 p. 1366. Idem: Proceedings of the Physiological Society, Journal of Physiology, vols. xxxi.-xliv., 1904. Idem: Ibid., vols. xxxvii.-xxxix., 1908. Geppert and Zuntz: Archiv fur die gesammte Physiologie, vol. xlii., 1888, p. 189. Haldane: Brit. Med. Jour., vol. ii., 1908, p. 578 Haldane and Priestley : Journal of Physiology, vol. xxxii., 1905, p. 225. F. W. Pavy : THE LANCET, Nov. 21st (p. 1499) and 28th (p. 1577) and Dec. 12th (p. 1727), 1908. Pembrey and Cook: Journal of Physiology, vols. xxxvii.-xli., 1908. Walter: Archiv für Experimentelle Pathologie und Pharmakologie, vol. vii., p. 148, 1877.

ON THE OPERATION OF CARDIOLYSIS : ILLUSTRATED BY A CASE. ${ }^{1}$

By F. J. POYNTON, M.D. LOND., F.R.C.P. LOND., ASSISTANT PHYSTCIAN TO UNIVERSITY COLLEGE hospital, ETC.; AND

W. TROTTER, M.S. LOND., F.R.C.S. ENG.,

ASSISTANT SURGEON TO UNIVERSITY COLLEGE HOSPITAL, ETO

THE operation of cardiolysis was first suggested in 1902 by Brauer and put in practice by Petersen - two names which to-day are associated with another and much more important advance in the surgery of the chest. The name cardiolysis is perhaps a little misleading, as it is at any rate more impressive than the surgically simple procedure to which it is given. It was pointed out by Brauer that in certain cases of adherent pericardium where the heart is embarrassed by fixation to the surrounding parts, a considerable amount of this overloading of the heart's action could be got rid of by rendering the præcordial part of the chest wall more flexible than normal by removing its bony and cartilaginous framework. No extensive separation of adhesions was suggested, and it is obvious that under the circumstances in which the operation has to be done such procedure would be very dangerous. In the first place the circulatory conditions are very unfavourable for prolonged general anæsthesia, while the risk of tearing the left pleura or even the heart wall would seem to be very great. The suggestion of Brauer was therefore prima facie an excellent one, and it obtained immediate practical justification in the operations done on his cases. The operation was extremely simple and short and the results were encouraging. Nevertheless, it seems to have been very little done. A review of the subject published in August, 1908, by Ernst Venus ${ }^{2}$ gives a total of 17 cases, three of them being Brauer's. The article contains a summary of all the cases and seems to be founded on a very complete study of the literature. There is no death recorded as the consequence of the operation, and the results appear on the whole to be very good.

In regard to the indications for operation there is a fairly general agreement amongst the various authors that those cases only are suitable in which the heart has shown some capacity for recovery under treatment by rest in bed. Clearly, if relief of the overloading of the heart is to be obtained by mobilisation of the præcordium, the capacity of the heart to recover must be demonstrable when the overloading is relieved by rest. It would seem then that the most suitable cases are those in which the heart is just inadequate for active life.

In all the published cases general anæsthesia seems to have been used, on the whole without much trouble. The operation need not last more than a few minutes and no very profound degree of anæsthesia is necessary, so that if the patient has been kept at rest for some time previously there

1 A paper read before the Clinical Section of the Royal Society of Medicine on May 14th, 1909. 